\title{
THE HUMAN SEMANTIC WEB SHIFTING FROM KNOWLEDGE PUSH TO KNOWLEDGE PULL
}

\author{
Ambjörn Naeve \\ The KMR (Knowledge Management Research) group \\ NADA (School of Computer Science and Communication) \\ KTH (Royal Institute of Technology) \\ 10044 Stockholm, Sweden \\ E-mail:amb@nada.kth.se \\ Web: http:/kmr.nada.kth.se
}

\begin{abstract}
This paper introduces the Human Semantic Web (HSW) as a conceptual interface, providing human-understandable semantics on top of the ordinary (machine) Semantic Web, which provides machine-readable semantics based on RDF. The HSW is structured in the form of a Knowledge Manifold and makes use of Unified Language Modeling (based on the Unified Modeling Language) combined with conceptual browsing to present its information to the user in a way that creates substantial benefits in terms of overview, clarity and flexibility. The HSW-browser Conzilla combines the semantics of RDF with the human-understandable semantics of UML in order to enable more powerful forms of human-computer interaction such as querying the Semantic Web through Edutella and supporting the concept-incontext methodology.
\end{abstract}

The Semantic Web is discussed in terms of three levels of semantic interoperability: isolation, coexistence and collaboration. Collaboration, as the highest goal, can be achieved by conceptual calibration, which builds bridges between different ontologies in a bottom-up way - describing their similarities as well as their differences. An example is presented in Conzilla of conceptual calibration between systems for e-commerce.

In the closing section, the Nonaka-Takeuchi theory of knowledge creation is discussed and the HSW is described as a "space for interaction", where the SECI spiral of knowledge creation can be elevated to the global level. Three possible scenarios are presented: "open research", "enriching the economy by expanding the value ontology", and "negotiating a sustainable future for all". 


\section{TABLE OF CONTENT}

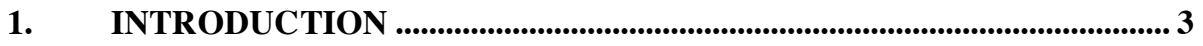

1.1. THE GLOBALLY ANNOTATED INFORMATION AGE …...................................... 3

1.2. NEW DEMANDS ON MANAGEMENT OF KNOWLEDGE AND LEARNING .............. 3

2. THE (MACHINE) SEMANTIC WEB ................................................... 4

2.1. SEMANTIC ISOLATION, COEXISTENCE AND COLLABORATION ........................ 5

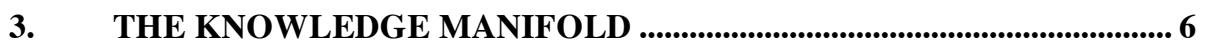

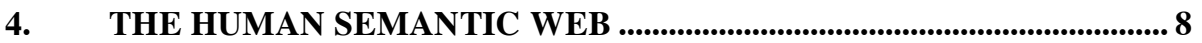

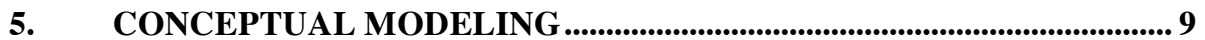

5.1. INTRODUCING THE CONCEPT 'CONCEPT' .................................................. 9

5.2. SOME PROPERTIES OF THE CONCEPT 'CONCEPT' .......................................... 10

6. UNIFIED LANGUAGE MODELING USING THE UML ....................... 10

6.1. CONCEPTUAL WEAKNESSES OF CLASSICAL UML .......................................... 10

6.2. THE Unified LANGUAGE Modeling TECHNIQUE....................................... 11

7. CONZILLA - A HUMAN SEMANTIC WEB BROWSER ....................... 14

7.1. HUMAN SEMANTIC QUERIES ON THE MACHINE SEMANTIC WEB ...................... 15

7.2. SUPPORTING THE CONCEPT-IN-CONTEXT METHODOLOGY.............................. 16

8. CONCEPTUAL CALIBRATION_........................................................... 17

8.1. THE ElECtronic COMMERCE INTEGRATION META-FrAMEWORK .............. 18

9. KNOWLEDGE CREATION ON THE HUMAN SEMANTIC WEB .... 21

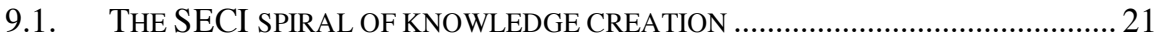

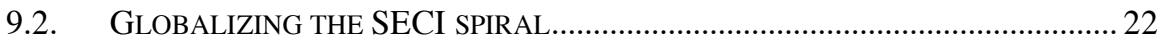

9.3. OPEN RESEARCH - A SCENARIO FROM THE MEDICAL DOMAIN ........................ 22

9.4. ENRICHING THE ECONOMY BY EXPANDING THE VALUE ONTOLOGY ............. 24

9.5. NEGOZILLA - NEGOTIATING A SUSTAINABLE FUTURE FOR ALL ..................... 25

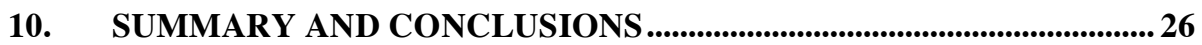

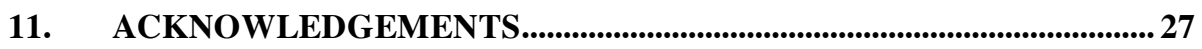

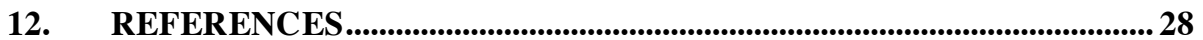




\section{INTRODUCTION}

\subsection{The globally annotated information age}

Recording, transmission and annotation of information are three fundamentally important human activities that have exerted a strong influence on social and cultural development. The invention of persistent recordings (such as e.g. Cuneiform writing) started the age of recorded information, and the invention of the Gutenberg printing press globalized the recording process and created the globally recorded information age. A few hundred years later, the emergence of electronic media globalized the transmission process and initiated the globally transmitted information age. Now, the emergence of the Semantic Web is globalizing the annotation process, thereby laying the foundation for the globally annotated information age.

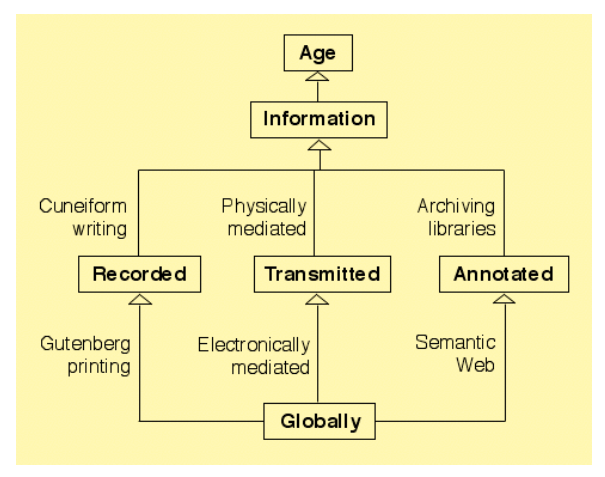

Figure 1. The Globally Recorded/Transmitted/Annotated Information Age

\subsection{New demands on management of knowledge and learning}

Due to the rapidly increasing use of information and communications technology, the amount of information that we have to deal with in our everyday lives has become much greater than only a few years ago, and this process has led to new ways of structuring information. Knowledge Management is a rapidly growing field of research, which studies these issues in order to create efficient methods and tools to help us filter the overwhelming flow of information and extract the knowledge that we need. Of course, the most complex information structure that we are dealing with today is the Internet, with its 'linked anarchy', where anyone can connect anything with anything else. It is a well known fact that - unless these anarchical powers are balanced by careful design - they easily result in web sites that are difficult to navigate and conceptualize as a whole, which in turn makes it hard for the human recipient to organize and integrate the separate components of information that are presented into a coherent pattern of knowledge. 
In [10], we ${ }^{1}$ define (mental) knowledge as consisting of efficient fantasies ${ }^{2}$ and describe (mental) learning as based on inspiring fantasies. Each fantasy has a context, a purpose and a target group, and it is only when we have described how we are going to measure the efficiency of our fantasies - within the given context, with the given purpose, and against the given target group - that we can speak of knowledge in a way that can be validated.

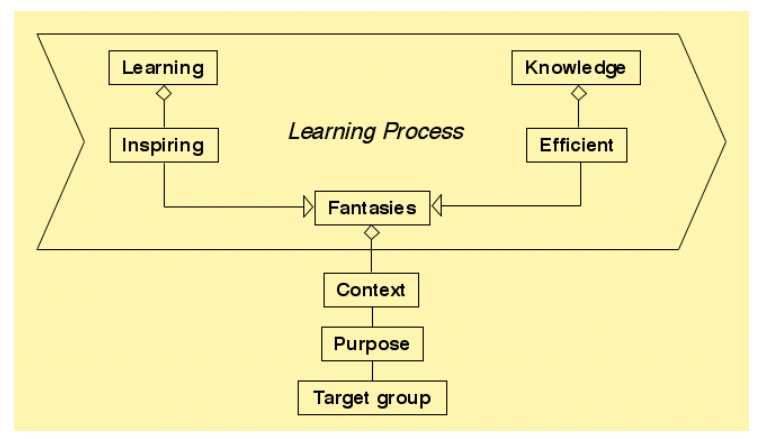

Figure 2. The learning process modeled as a transformation from inspiring to efficient fantasies

With this definition, learning management is concerned with exposing the learner to inspiring fantasies and assisting her/him in transforming them into efficient fantasies. Within a learning organization, this is closely related to knowledge management, which is concerned with creating, collecting, maintaining and presenting knowledge in a way that makes it available within the organization wherever and whenever it is needed.

Life long, flexible, collaborative, and personalized learning are words that are increasingly used in places where education is discussed and designed. They express important wishes that put new demands on learning architectures, with regard to pedagogy, organization and technology. The traditional learning architectures are based on teacher-centric, curriculum-oriented, knowledge-push. The new demands are largely concerned with a shift along all of these dimensions in order to support more learner-centric, interest-oriented, knowledge-pulling types of learning architectures. At the same time, within most organizations, new demands are being placed on effective knowledge management. Promoting the creation and sharing of knowledge in order to assure the right person with the right knowledge in the right place at the right time at the right cost is the overall aim of these demands.

\section{THE (MACHINE) SEMANTIC WEB}

On the Internet of today, the information is distributed and anyone can link anything to anything. After all, this is what has made the web such a great success. However, the information about the information - the metadata - is still largely centralized and

\footnotetext{
${ }^{1}$ Throughout this article, the term 'we' - when not used to involve the reader in the discussion - will refer to the Knowledge Management Research (KMR) group [31] at KTH, which I am leading.

${ }^{2}$ As opposed to muscular knowledge, which could be defined as efficient reflexes. The word "fantasy" is used instead of the more or less synonymous word "conceptualization" in order to emphasize that the conceptual structures are constructed from within.
} 
resides in databases that are hidden behind web portals. These portals are advertised by their address, with the implication: "Come to our portal and search our database(s)". This stage of web development could be described as "semantic isolation". It is characterized by the fact that you have to know where a database is located in order to be able to search in it. Also, the information on an ordinary HTML web page is not represented in a way that is interpretable by machines. As an example, imagine that you want to find all the books written by Shakespeare. If you type the words "book" and "Shakespeare" into Google and hit "search", you will get hits on web pages that state things like "this book is NOT written by Shakespeare".

On the Semantic Web, the information about the information can be represented in such a way that you can find the books written by Shakespeare ${ }^{3}$. This is most often done by the use of an ontology [2], which consists of a set of formally defined terms with relations between them and (possibly) restrictions in the way that they are used. An ontology is a form of conceptual model, whose structure is similar to that of a thesaurus, with its use of "broader" and "narrower" terms, "part-of" relationships etc.

Moreover, on the Semantic Web the information about the information can be as distributed as the information itself without loosing track of what the information is referring to. Hence, anyone can state anything about anything in a way that is retrievable by machines ${ }^{4}$. This is possible because - on the Semantic Web - even if our statements are made in different contexts, a machine can decide whether or not we are talking about the same thing - as opposed to deciding what we are talking about, which will never be possible for a machine. Hence the semantics of the expression "Semantic Web" is rather misleading, and a more semantically correct label on this kind of web would be the identity-resolvable web.

\subsection{Semantic isolation, coexistence and collaboration}

Describing your information on the Semantic Web makes this metadata available for machine processing, and the things you describe become uniquely identifiable. Using semantic wrapping techniques ${ }^{5}$, a database can inform the web about which kind of questions that it holds answers to, making it possible to search the database without knowing in advance where it is located. This stage of web development could be described as "semantic coexistence".

However, there is still no way to know how your descriptions are related to those of others. In order to make this possible you have to relate these descriptions to each other, by creating some form of "semantic mapping" between them. For example, one repository might use the term "author" while another might use the term "creator" to describe a person that has written a book. In order to search for books written by Shakespeare in both repositories using the same query, we must - in the case of books - connect the terms "author" and "creator" so that a machine can figure out that they refer to the same thing. In this way, when a set of description structures (ontologies) have been related by a semantic mapping (ontological bridge), it is possible for a machine to relate them to each other, which is a prerequisite for

\footnotetext{
${ }^{3}$ The technical basis for this are the description languages RDF(S) [46] and OWL [47].

${ }^{4}$ e.g. through the Edutella infrastructure [12], [40].

${ }^{5}$ Such as e.g. AMOS/PSELO developed by Uppsala DataBase Laboratory [41].
} 
achieving the much desired capability of semantic interoperability. This stage of web development could be described as "semantic collaboration".

To summarize this discussion, we list some characteristics of the three different semantic stages outlined above?

Semantic Isolation:

- XML (or other "semantically free" formats).

- Document-based descriptions.

- Closed description spaces.

- Fixed metadata set (tags and values).

- Databases with entry-portals.

- No joint searching (inter-search).

Semantic Coexistence:

- $\mathrm{RDF}(\mathrm{S})$.

- Graph-based descriptions.

- Open description spaces.

- Freely evolving metadata (tags and values).

- Databases with Edutella connections.

- Joint searching (inter-search) with static queries.

- Retrieval.

Semantic Collaboration:

- Ontology management systems.

- Ontology mappings.

- Contextualization.

- Controlled evolution of metadata.

- Joint searching (inter-search) with dynamic queries.

\section{THE KNOWLEDGE MANIFOLD}

The research of the KMR group revolves around a structured information architecture that is called a Knowledge Manifold [5], [6], [8], and which supports a number of different strategies for the suppression and presentation of information. A $\mathrm{KM}$ consists of a number of linked information landscapes (contexts), where one can navigate, search for, annotate and present all kinds of electronically stored information. A KM is constructed by conceptual modeling of a specific knowledge domain in order to capture its underlying thought patterns in the form of contextmaps.

By defining a conceptual model (ontology) the concepts acquire an outside and an inside. In fact, a single concept acquires several outsides, since it can appear in several different contexts. In KM terms we make the following:

\footnotetext{
${ }^{6}$ An important step towards semantic collaboration is abstract modeling, which allows both sides of an ontological bridge to be treated as instantiations of the same abstract model. See [24] for an application to the Dublin Core Metadata Initiative [56].

${ }^{7}$ For a more detailed description of these matters, the reader is referred to [11].
} 
Def: Let $C$ denote a concept. An outside of $C$ is called a context for $C$, and the inside of $C$ is called the content of $C$.

Hence, in a Knowledge Manifold, the fundamental relationship between concept, context and content can be summarized as:

content in context through concept.

The knowledge manifold architecture can be used as a framework for the construction of interactive learning and knowledge management environments that enable a learner-centric, interest-oriented form of 'knowledge-pull', and which support inquiry-based and personalized forms of networked learning [11]. An important design goal is to support the transformation of the teaching role - away from the traditional "knowledge filter" towards more of a "knowledge coach", i.e. away from "teaching you what I know" and towards "helping you to find out more about the things that you are interested in".

The knowledge manifold educational architecture is based on the following fundamental pedagogical assumptions [8]:

- Nobody can teach you anything. A good teacher can inspire you to learn.

- Your motivation to learn is based on the experience of subject excitement and faith in your learning capacity from live teachers.

- Your learning quality is enhanced by taking control of your own learning process.

- No 'problematic' questions can be answered in an automated way. In fact, it is precisely when your questions break the pre-programmed structure that the deeper part of your learning process begins.

A Knowledge Manifold consists of a number of linked knowledge patches - each maintained by a custodian called a knowledge gardener. A knowledge patch in turn consists of a set of content components, or resource objects ${ }^{8}$, that are tied together with context-maps that represent the corresponding conceptual model of the subject domain, and whose concepts (and concept-relations) can be filled with content ${ }^{9}$. Such context-maps are preferably constructed using the ULM technique described in section 6.2. A concept browser [7] lets the user navigate the context-maps and view their content filtered by a configurable set of context-dependent aspects [23].

When used for learning purposes, the KM architecture supports the following seven different knowledge roles [8]:

- the knowledge cartographer, who constructs and maintains context-maps.

- the knowledge librarian, who fills context maps with content components.

- the knowledge composer, who constructs customized learning modules.

- the knowledge coach, who cultivates questions.

- the knowledge preacher, who provides live answers.

- the knowledge plumber, who directs questions to appropriate preachers.

- the knowledge mentor, who is a role model and supports self-reflection.

\footnotetext{
${ }^{8}$ In KM terminology, we use the term knowledge object, when we assume the perspective of the teacher(s), the term information object (or learning object) when we assume the perspective of the learner(s), and the term resource object when want to remain neutral in this respect.

${ }^{9}$ This supports the separation of content from context, which promotes the reuse of content across different contexts.
} 
The KM architecture can be seen as a contribution towards the vision of a semantic learning web, as stated in [13]: "a learning web infrastructure, which will make it possible to exchange / author / annotate / organize and personalize / navigate / use / reuse modular learning objects that support a variety of courses, disciplines and organizations".

\section{THE HUMAN SEMANTIC WEB}

The stated goal of the Semantic Web initiative [48] is to enable machine understanding of web resources. However, it is not at all evident that such machinereadable semantic information will be clear and effective for human interpretation. The hyperlinked structure of the web presents the user with a totally fluid and dynamic relationship between context and content, which makes it hard to get an overview of the context within which the information is presented. As soon as you click on a hyperlink, you are transferred to a new and often unfamiliar context. This results in the all too well known "surfing-sickness", which could be summarized as "Within what context am I viewing this, and how did I get here?" [7] The conclusion is that extracting usable meaning from web pages is often as difficult for a human reader as it is for a machine. This strongly suggests that there is a need for a humanunderstandable semantics for web resources as well.

Hence, in order to effectively harness the powers of the semantic web, it needs a "conceptual interface" that is more comprehensible for humans. We conceive this conceptual interface as a form of Knowledge Manifold, which we call the Conceptual Web [9] or the Human Semantic Web. The HSW is a mixture between conceptual and pictorial "information landscapes" that are linked in the structure of a Knowledge Manifold. It serves as a human-understandable front-end that connects to the "machine-understandable" back-end of the (machine) semantic web.

It is important to emphasize the following (often neglected) facts about metadata ${ }^{10}$ :

- Metadata is not always objective - it must also allow subjective expressions.

- Metadata is not produced once and for all - it is the result of an ongoing annotation process, which, ideally, should produce an 'ecosystem' of annotations that highlight resources with high quality.

- Metadata is not a collection of documents, but a global network of information.

- Metadata is not only for machines. We need conceptual metadata for people.

An important feature of the HSW is the ability to collect metadata from various sources into suitable contexts. These contexts can then be presented in various graphical user interfaces, such as adorned forms, through diagrammatic languages such as UML etc. Such contexts are also usable for the human management of evolving metadata [14].

The different contexts of the HSW are described by context-maps that are constructed by conceptual modeling and connected through the knowledge manifold architecture. This provides a "conceptual information atlas" of connected contextmaps with human-understandable semantics for both abstract ideas and concrete

\footnotetext{
${ }^{10}$ further discussed in [14].
} 
resources. As discussed in section 6.2, for the conceptual modeling we make use of the ULM (Unified Language Modeling) technique ${ }^{11}$, which is tailored to support the visualization of how we speak about things. UML provides a well-proven and standardized modeling vocabulary with clearly defined visual semantics of the relationships between the occurring concepts.

Combining the human semantics of UML with the machine semantics of RDF [45] enables more efficient and user-friendly forms of human-computer interaction. The HSW supports the mixture of human- and machine semantics that is needed for efficient construction and use of modular and personalized learning and knowledge management environments based on retrieval and reuse of relevant knowledge resources.

In general, the HSW is designed to support the ongoing "paradigm shift" of social interaction patterns from knowledge-push to knowledge-pull, such as the shift:

- from teacher-centric to learner-centric education.

- from doctor-centric to patient-centric health care.

- from bureaucrat-centric to citizen-centric administration.

- from government-centric to citizen-centric democracy.

- from producer-centric to consumer-centric business models.

\section{CONCEPTUAL MODELING}

Wittgenstein has demonstrated that we cannot speak about things in their essence [30]. In fact, we attach names to things in order not to have to talk about whatever lies behind these "verbal interfaces" to the unknown. Instead, we talk about the only things that we can talk about, namely the relations between the cognitive appearances of things. This fundamental fact forms the basis of the entire scientific project, so clearly stated by one of its most eminent proponents - Henri Poincaré:

The aim of science is not things themselves - as the dogmatists in their simplicity imagine - but the relations between things. Outside those relations there is no reality knowable ([25], p. xxiv).

Hence, according to Poincaré, the conceptual relationships are fundamental to any linguistically based world model, because they represent the only things that we can talk about.

\subsection{Introducing the concept 'concept'}

Concept formation helps us to disregard what is inessential by creating idealized structures that focus on what is essential. Efficient concepts disregard as much as possible in such a way that it is noticed as little as possible ${ }^{12}$. Classical examples of efficient concepts are "Point", "Line" and "Plane" from the field of geometry.

There is a vast literature on conceptual modeling. Here we will just give a brief summary of some important definitions related to the concept "concept" from the

\footnotetext{
${ }^{11}$ based on the UML (Unified Modeling Language [58]).

${ }^{12}$ The power of thinking lies in knowing what NOT to think about.
} 
perspective of object-oriented modeling. For a more thorough discussion, the reader is referred e.g. to [19].

Def: A concept is a representation of something that we have experienced or that we can imagine, and which we can apply to the objects that we are aware of.

Def: A description of the most important concepts - and their relations - within a specific problem domain is called a conceptual model of the domain.

Def: The definition of a concept describes its intention, i.e. what qualities it aims to express and delimit with respect to its surroundings.

Def: The set of objects that exemplify a concept is called its extension.

Def: Each member element of the extension-set is called an example $=$ object $=$ instance of the concept.

Def: The concept, whose extension consists of a set of instances, and whose intention describes their common structure, is called the type or the class of these examples.

Def: To identify a concept by observing similarities and differences within a group of examples is called to classify the examples.

Def: We say that a concept can be applied to a specific example, if this example fulfills the intention of the concept.

\subsection{Some properties of the concept 'concept'}

- A concept must always be defined by making use of other concepts.

- A concept can be denoted by one or several names (= symbols).

- A concept is always idealized, because it contains simplifications that focus on some properties and disregard others.

- The definition of a concept always depends on the context within which it will be used. The aim is always to disregard the inessential and focus on what is essential.

\section{UNIFIED LANGUAGE MODELING USING THE UML}

UML (Unified Modeling Language [26], [58]) is a language for specifying, visualizing and documenting conceptual models within many different knowledge domains. UML was developed during 1993-1997 within the object-oriented software community as an attempt to unify the more than 250 different modeling languages that were in use for software modeling by the mid 1990s. UML represents a collection of practically tested modeling techniques that have proven to be effective in the description of large and complex systems. Today, UML is a de-facto industry standard for systems modeling.

\subsection{Conceptual weaknesses of classical UML}

Although it has many different uses, UML was created in order to model software systems - mostly to be implemented in strongly typed languages such as $\mathrm{C}++$ or Java. This implies a sharp division between compile-time information - expressed in relationships between types, and run-time information - expressed in relationships between instances. This difference is reflected most clearly in the way that UML separates between class diagrams (dealing with types and their relations) and instance diagrams (dealing with instances and their relations).

\footnotetext{
${ }^{13}$ i.e. the conditions of its definition.
} 
Closely related to the strong separation between types and instances is the unfortunate instance notation in UML, as shown in the left part of Figure 3. From a structural (mathematical) perspective, it weakens the representational power of a language to represent a relation between two concepts ${ }^{14}$ on one of the concepts involved - instead of on the connection between them. This "design weakness" makes it practically impossible to express several levels of the instance-type relationship in UML. Of course, when you are modeling with the aim to create software, this is not a severe restriction, since you normally think of the types as classes, and represent them in a class-diagram. They represent the compile-time view of the system. The instances, on the other hand, represent the run-time view of the system. Instances are born in multitudes and they live a hectic - and often brief - life, that is illustrated with partial snapshots in the form of UML instance diagrams. Here UML reveals its close historical ties with the object-oriented community, which has been dominated by static, single-level typed languages such as $\mathrm{C}++$ and Java.

What is needed in order to remedy this weakness is to notationally express the instance-type relationship in a way that reflects its true nature, namely as a conceptual relationship. We will introduce a notation for the instance-type relationship in the next section

Moreover, in ordinary language, types are generally referred to without a prefixing article (determined or undetermined), e.g. "this Volvo is of type Car", while instances are generally referred to with a determined or undetermined article, e.g. "the Car", "this Car", "a Car". In contrast, within the object-oriented modeling community there is a tradition of denoting the inheritance relationship with "is $a$ ", e.g "Car is a Vehicle", as expressed in the left part of Figure 5. This breaks the linguistic coherence of the model, since it compares "Car" to " $a$ Vehicle" at the same type level.

\subsection{The Unified Language Modeling technique}

Unified Language Modeling ([5], [6], [7]) is a context-mapping technique, which has been developed during the past decade. It is designed to visually represent a verbal description of a subject domain in a coherent way. Today, the ULM technique is based on the Unified Modeling Language, which is a de facto industry standard for systems modeling.

In ULM the resulting context-maps have a clearly defined and verbally coherent visual semantics, which makes it easy to cognitively integrate the conceptual relations and achieve a clear overview of the context. Moreover, making the context visually explicit provides important support for the conceptual calibration activities ${ }^{15}$ that are necessary in order to achieve semantic collaboration. The ULM verbal-tovisual contextual representation technique has a crucial advantage in comparison with similar techniques - such as concept maps [18], [59] or topic maps [60] - which have to rely on purely verbal semantics in order to convey their conceptual relationships.

\footnotetext{
${ }^{14}$ in this case the property that something is to be regarded as an instance of something else, which is to be regarded as its type.

${ }^{15}$ Described in Chapter 8 below.
} 
In order to be able to correctly interpret the context-maps of this article, we will give a brief description of some of the extra notation introduced in ULM in comparison to $\mathrm{UML}^{16}$.

As discussed above, UML represents the example-type (instance-type) relation on the instance itself - as shown in the left part of Figure 3, which shows that the depicted concept is an (unnamed) instance of type car. The right part of the figure shows the same relation represented in ULM. The dashed arrow (with a small filled head) represents the classification/instantiation, and is pronounced "is $a$ " when read along the direction of the arrow, and " $a$ " when read in the opposite direction. Hence the language interpretation of the right part of Figure 3 is " $a$ Car is $a$ Car", which is a purely tautological statement. Here the indefinite article (" $a$ ") serves as an instantiation operator (providing the example) and the "is $a$ " serves as a classification operator (providing the type of the example).

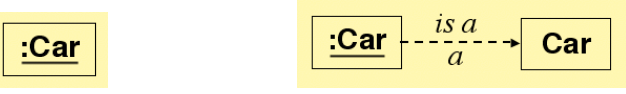

Figure 3. ULM: a Car is a(n instance of type) Car

In this way ULM decouples the description of the concept (the specific car instance) from the relationship to its type (Car). This addition to classical UML achieves two important benefits:

- It makes it possible to describe several levels of the example-type relationship. Figure 4 shows an example of this, which cannot be expressed in classical UML.

- It corrects the unfortunate traditional notation from the object-oriented community, where "is a "denotes the generalization/specialization relationship as shown in the left part of Figure 5. This relation should instead be called "kind of", as shown in the right part of Figure $5^{17}$.

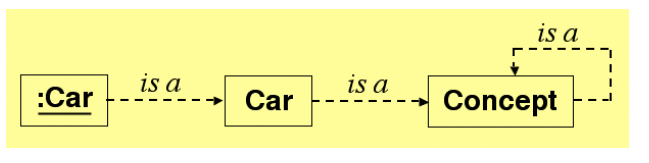

Figure 4. a Car is a Car is a Concept is a Concept is a ...

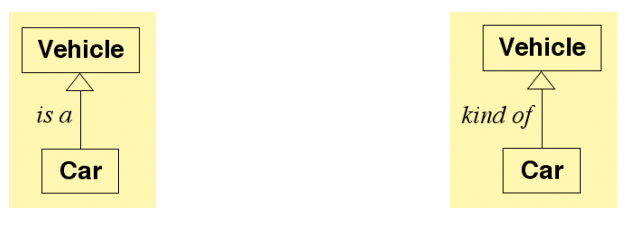

Figure 5. Traditional OO: Car is a Vehicle. ULM: Car kind of Vehicle

\footnotetext{
${ }^{16}$ Technically speaking, ULM can be regarded as a profile of UML, which defines some special notation that is useful in order to draw how we talk about things.

${ }^{17}$ In UML this relation is called gen/spec (generalization/specialization), which gives no clue as to how to read out the relations in a coherent way. Both "is a" and "kind of" are used for reading the gen/spec arrow along its direction.
} 
These notational changes open the way for descriptions that can combine relations in a diagrammatically correct way, and which translate from the visual to the verbal in a coherent manner. Figure 6 shows an example of how this works. Here we see how the statements " $a$ Car is a Car" and "Car kind of Vehicle" are combined (both diagrammatically and verbally) into the statement " $a$ Car is a kind of Vehicle".

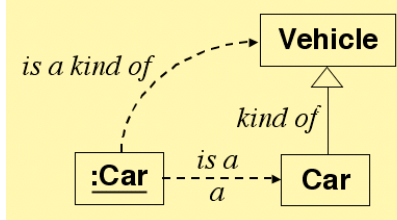

Figure 6. The verbal-visual coherence of ULM

The basic visual to verbal coherence of the ULM technique is shown in Figure 7.

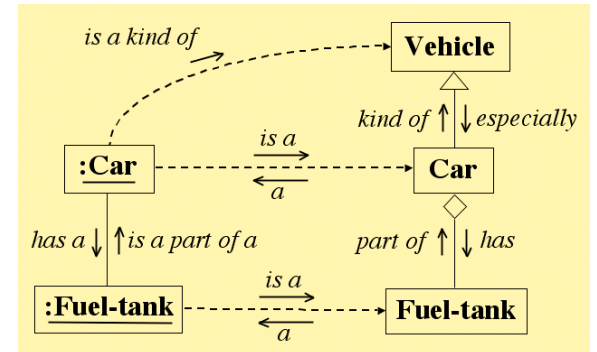

Figure 7. The basic verbal/visual correspondence of Unified Language Modeling.

The statements " $a$ Fuel-tank is $a$ Fuel-tank", and "Fuel-tank part of Car", are combined into the statement " $a$ Fuel-tank is a part of a Car", showing the difference between the gen/spec and the aggregation relationships. The former expresses the structure of a single instance (" $a$ Car is a kind of Vehicle"), while the latter expresses a link between two instances of the corresponding types (" $a$ Fuel-tank is a part of a Car"). Notice also how the latter relationship is expressed in the opposite direction: The statement "Car has Fuel-tank" is transported by the instantiation operator (the indefinite article " $a$ ") into the statement " $a$ Car has a Fuel-tank". 


\section{CONZILLA - A HUMAN SEMANTIC WEB BROWSER}

During the past 7 years, we have developed a prototype of a concept browser [7], called Conzilla, [20], [34]. Since Conzilla is carefully designed with a clear objectoriented structure that separates the underlying logic from the presentation and style graphics, it can easily be adapted to different presentational styles and cognitive profiles $^{18}$. Several Conzilla-based knowledge manifolds have been constructed, e.g. within the fields of mathematics, IT standardization and interoperability between different systems for e-commerce [51].

A concept browser is a powerful tool with a multitude of potential applications, and Conzilla is attracting increased attention both on the national and the international level. Within the framework of the Human Semantic Web, we are aiming to develop Conzilla into a generic information management tool by participating in collaborative projects that will expand the capabilities of the program within the rapidly converging areas of learning and knowledge management - focusing on the domains of e-learning, e-commerce and e-administration ${ }^{19}$.

In February 2005 we released Conzilla2, which is a Human Semantic Web browser, or a conceptual interface to the (machine) Semantic Web. Its main requirements are that it should:

- serve as a collaboration tool for more or less formalized modeling techniques, most notably UML dialects.

- simplify the task of creating information according to various metadata standards.

- support customized presentations of information without requiring duplication or modification of information sources.

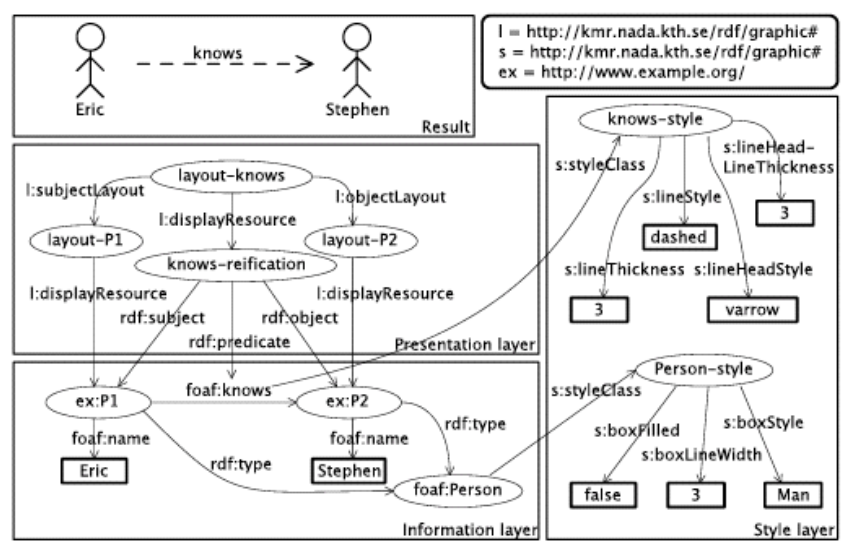

Figure 8. The representation in Conzilla2 of the fact that "Eric knows Stephen" ${ }^{20}$

\footnotetext{
${ }^{18}$ Conzilla is being developed as an open source project at SourceForge, and can be downloaded from www.conzilla.org.

${ }^{19}$ In accordance with the e-Europe initiative [50], we are also aiming for Conzilla to support increased e-accessibility by enabling it to configure itself to different cognitive profiles.

${ }^{20}$ This picture is taken from [20], where Conzilla2 is described in detail.
} 
These requirements are fulfilled by choosing a three-layered approach for working with semantic web information in Conzilla, namely the information-, presentationand style layers. Figure 8 shows these three representation layers resulting in the topleft context-map, which displays the fact that "Eric knows Stephen".

\subsection{Human semantic queries on the machine semantic web}

As mentioned in section 2, the Semantic Web offers unprecedented opportunities for precise querying and searching for information about various resources. Edutella [12], [15], [29] is a peer-to-peer network infrastructure for search and retrieval of information about resources on the Semantic Web that takes advantage of these opportunities. Edutella builds upon metadata standards defined for the WWW and provides an RDF-based metadata infrastructure for P2P applications, building on the JXTA Framework [39].

To show the kind of queries that Edutella can manage, consider the query depicted in Figure 9 (as a simplified RDF graph). $X$ represents the resource we are looking for, and the arcs are properties of that resource. In plain English, the query asks for the following (in counter-clockwise order):

All Scientific Works on the subject of Politics, having Lebanon as subject or keyword, with a title (Y), written in English, German or French, created or contributed to by a Person (Z), employed at a University, and created after $1980^{21}$.

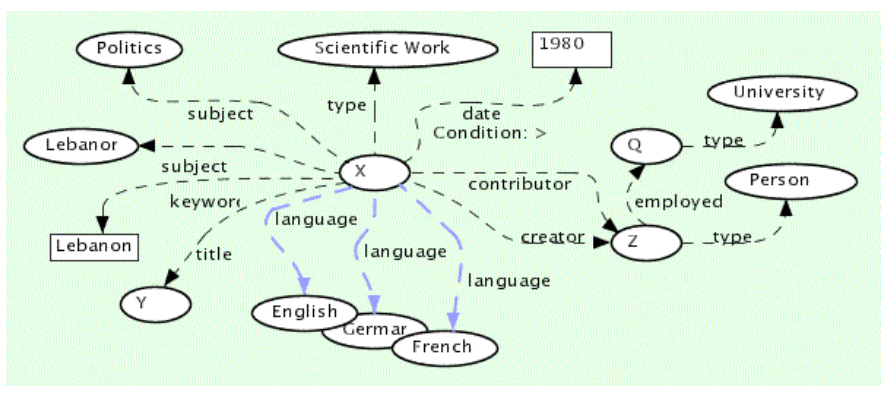

Figure 9. An Edutella query expressed in (simplified) RDF. It is directed towards the (machine) Semantic Web and not very understandable for humans.

Edutella takes queries of the above complexity, distributes them to peers that have declared themselves capable of answering this type of query, collects the answers and returns them to the originator. It is possible that parts of the answers are located on different peers. In the example, the university employee information is perhaps not located on the same server as the resource metadata, but Edutella is able to handle these kinds of situations in a transparent manner [15].

Although the Edutella query depicted in Figure 9 is logically precise and easy for machines to process, it is not very understandable for humans. When the queries are formulated by humans, as opposed to e.g. by agents, there is a need to represent them in a more humanly understandable form. Figure 10 shows the same Edutella query

\footnotetext{
${ }^{21}$ Note that there are several occurrences of "or" in this transcription. However, this information is not explicit in the figure, but is represented separately.
} 


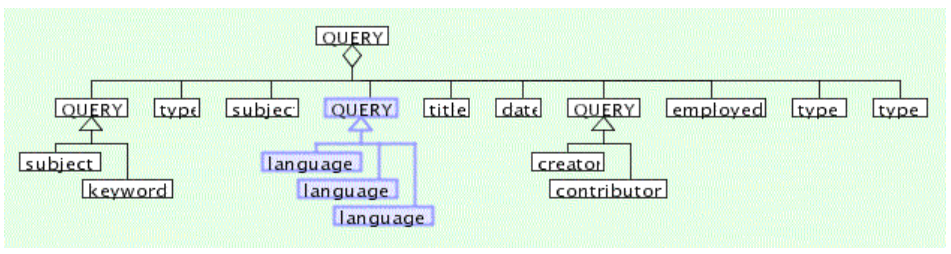

Figure 10. The same Edutella query presented on the Human Semantic Web through a queryinterface in Conzilla (with most of the information hidden)

presented on the Human Semantic Web through a query interface in Conzilla. Here the query is formulated as a Boolean tree - with "or" expressed as a UMLgeneralization and "and" as a UML-aggregation, which have the corresponding semantics.

\subsection{Supporting the concept-in-context methodology}

The rapidly increasing internationalization and professionalism of higher education is dependent on the methodology and the quality of the supporting ICT tools. In this context, projects like Sakai [49] are blazing a new trail. Instead of leaving the development of quality tools and services needed by the university to the commercial actors, these two projects have taken the lead by having member institutions collaboratively develop an open source portal and learning system. Currently more than 65 institutions from 10 countries are Sakai members and participate in the development of the Sakai system. In addition, many other schools, including K-12, community colleges, and universities, are interested in adopting the open source Sakai toolkit. Use of Sakai on a large scale at many universities provides a good opportunity to introduce new methodologies and new ways of teaching.

At the time of writing of this article, we are involved with Sakai in defining a project that aims to help students achieve better learning outcomes by the collaborative construction of "Human Semantic Learning Webs", accessed through supportive, well-integrated ICT-based frameworks and technologies. The project proposes integration of our concept-mapping methodology - called concept-in-context - into Sakai. This methodology encourages students and teachers to externalize what is being learned, by expressing concepts and their relations in various contexts. The methodology has been tested with various student groups at KTH [1] over the past few years with promising results ${ }^{22}$. The explicit aims of the concept-in-context methodology are:

- to capture the communication situation when several learners/teachers collaboratively work on a sheet of paper or whiteboard to sketch their ideas/common understanding of an area.

- to assist teachers and students in expressing thoughts on learning material and learning processes at the conceptual level.

- to support the formation of new knowledge by relating it to already established knowledge. $^{23}$

\footnotetext{
22 mainly students at the Media technology program.

${ }^{23}$ This is achieved by encouraging reuse, annotation and refinement of concepts.
} 
The concepts and concept-relations in this methodology are collected into browsable maps providing an overview and a collaborative workspace. Individual concepts may be enriched with examples such as connections to course material, rich explanations, and relations to other concepts. The maps will be accessible through tools that will be integrated into the Sakai framework.

A crucial feature of the concept-in-context methodology is that concepts have a life independent of their occurrence in context-maps. Their properties can be highlighted in one or several maps but, in most cases, their full nature lies beyond the digital domain. Hence, some knowledge will always remain tacit - in the mind(s) of the individual or group responsible for expressing the concepts. Consequently, it is vitally important to keep track of who expressed what.

The contextual independence of concepts opens up the possibility of their reuse. For instance, concepts may be reused:

- by teachers in multiple courses, perhaps related to other concepts in the process.

- by learners for making connections and comments on what is learned. This could be for personal use, as a way to communicate with fellow learners, or to prove to someone else that you have reached a deeper level of understanding.

To support collaboration, maps and concepts cannot be exclusively owned. Consequently, when looking at a map or an individual concept, the user can choose to include or exclude various contributions made to it. Typically a student investigates a map made by the teacher(s), and then chooses to include extensions from other fellow students in the same year or perhaps students that have taken the course earlier years. The student may go on and make extensions and comments on the map, typically adding some concepts or relations between concepts. Before moving on, s/he has to decide if her/his changes are for everyone to see, to be shared with a limited group of people or not to be shared at all.

\section{CONCEPTUAL CALIBRATION}

Semantic collaboration, as described in section 2.1, can be approached in two fundamentally different ways: top-down or bottom-up. The top-down approach involves designing a common ontology from agreed-upon fundamental concepts, a process that basically requires the reaching of consensus among all participating stakeholders. The bottom-up approach, on the other hand, starts from the existing conceptual models of the participating calibration partners and tries to model both the similarities and the differences between these models. This is a more complex process than the top-down approach, but it has the great advantage that consensus does not have to be reached.

A bottom-up approach to achieving semantic collaboration can be carried out through the process of conceptual calibration described in [5]. This process consists of three different activities:

(i) Agreeing on what we agree on.

(ii) Agreeing on what we don't agree on.

(iii) Documenting (i) and (ii) in a way that we agree on. 


\subsection{The Electronic Commerce Integration Meta-Framework}

As an example of the conceptual calibration technique, we will consider the case of e-commerce systems, where the KMR group has been involved in a standardization project called ECIMF ${ }^{24}$ [51] within the CEN/ISSS Electronic Commerce workshop. The proliferation of mutually incompatible standards and models for conducting ecommerce (resulting from the isolated efforts of industry groups and standard bodies) have created quite the adverse effect from what was intended, when it comes to wide acceptance of electronic commerce, especially in the $\mathrm{SME}^{25}$ market. The industry is looking for methods to meet the exploding demand for increased quality of service, reduction of manual labor and cost, and to meet the requirements of nearly real-time reaction to changing market demands. However, the existing e-commerce frameworks require costly adjustments in order to fit a specific business model to that of a specific framework, with the perspective that similar costs will follow if the business party wants to participate in other frameworks as well.

In response to these concerns from the industry, the CEN/ISSS Workshop for Electronic Commerce has carried out the E-Commerce Integration Meta-Framework (ECIMF) project ${ }^{26}$, which has aimed to deliver:

A meta-framework, which offers a methodology, a modeling language and prototype tools for all e-commerce users to achieve secure interoperability of the service regardless of system platforms and without major adjustments of existing systems.

An important premise of the project is the following definition of interoperability:

Interoperability, as seen from the business point of view, takes place when the business effects for the two involved enterprises are the same as if each of them were conducting a given business process with a partner using the same e-commerce framework.

The ECIMF project has built on the experiences from projects such as ebXML [52], UN/CEFACT Unified Modeling Methodology [53], RosettaNet [54], BizTalk [55], and various Web Services initiatives. An extended version of Conzilla has been used as an experimental platform for the project. The extensions were specifically constructed in order to support the conceptual calibration methodology that was described above.

The ECIMF makes use of three different types of models, the semantic model, the dynamic model and the syntactic model. For each e-commerce system involved, these models are constructed in a top-down manner, combined with an iterative process of refining the higher level models based on the additional information gathered in the process of modeling the lower levels, as shown in the left part of Figure 11. Here we will briefly illustrate the alignment methodology of the semantic models, since it makes use of the bottom-up conceptual calibration technique described above.

\footnotetext{
${ }^{24}$ Electronic Commerce Integration Meta Framework.

${ }^{25}$ Small- and Medium-sized Enterprises.

${ }^{26}$ Between February 2001 and February 2003.
} 

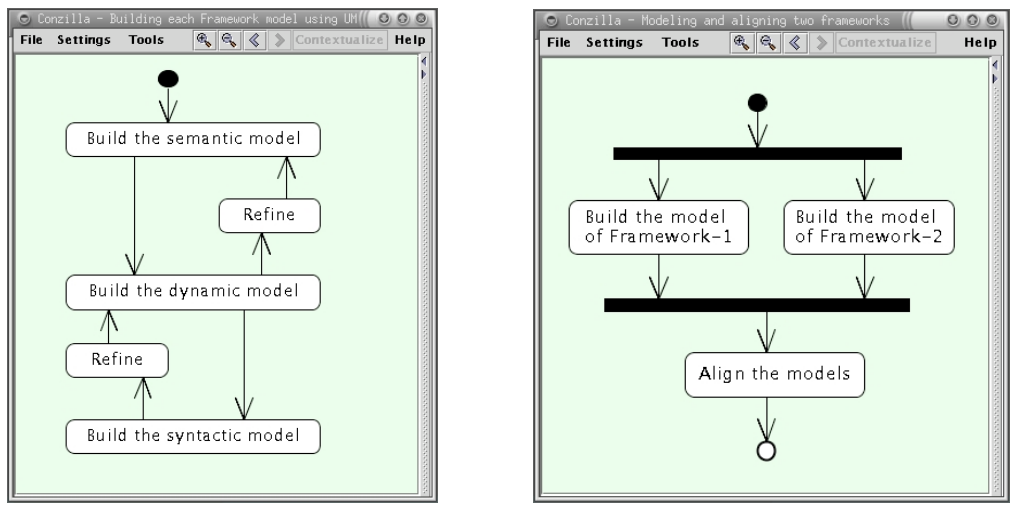

Figure 11. Overview of the ECIMF methodology

Figure 12 shows the Conzilla approach to the alignment of the two semantic models in a highly simplified artificial example. The left and right top windows of Figure 12 show UML diagrams of the two semantic models, and the bottom window shows three Conzilla comparators, called 'Agent/Party', 'Message/Document' and 'BusinessProcess/Conversation'. Each comparator connects the corresponding concepts of the two models in such a way that when the comparator is highlighted, so are the corresponding concepts. In Figure 12, the comparator 'Agent/Party' has been highlighted, showing that 'Agent', 'ServiceEntity' and 'BusinessEntity' in framework 1 correspond to 'Party', 'User' and 'Role' in framework 2.

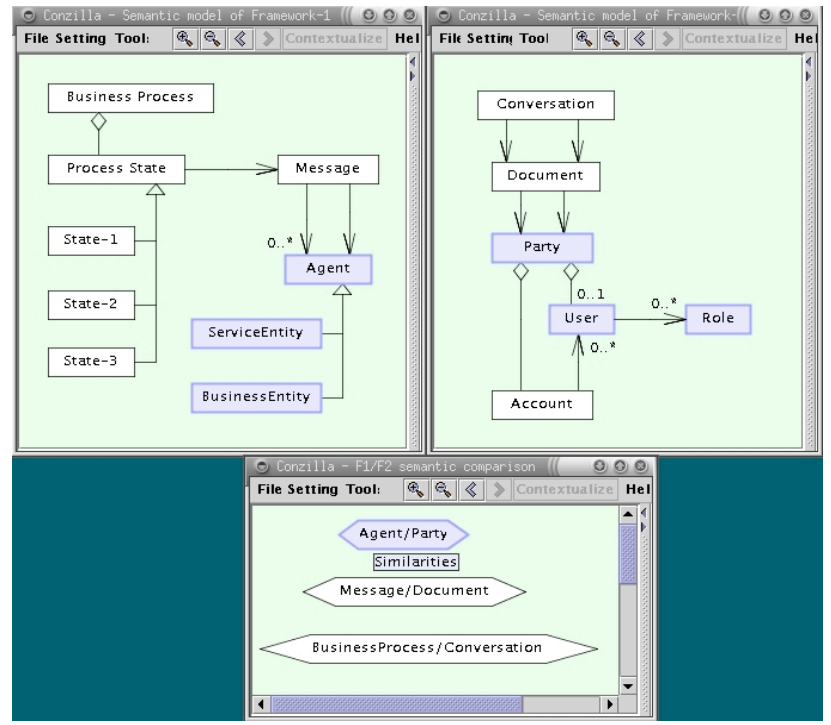

Figure 12. The top windows show the semantic model of framework 1 (left) and framework 2 (right). The bottom window shows three Conzilla comparators. Highlighting the 'Agent/Party' comparator shows the corresponding parts of the two models.

Moreover, each comparator is linked to a semantic comparison window, where the similarities and differences of the corresponding parts of the two models are described. For example, double-clicking the 'Agent/Party' comparator (Figure 13) opens the corresponding semantic comparison window (bottom left), where the similarities and the differences between the 'Agent/Party' sections of the two models 
are described. The dotted lines show that 'Agent' corresponds to 'Party' while 'ServiceEntity' and 'BusinessEntity' correspond to 'Role'. Highlighting a concept in any window (e.g. 'Agent' as in Figure 13) will highlight it and its corresponding concepts (in this case 'Party') in all windows where these concepts appear.

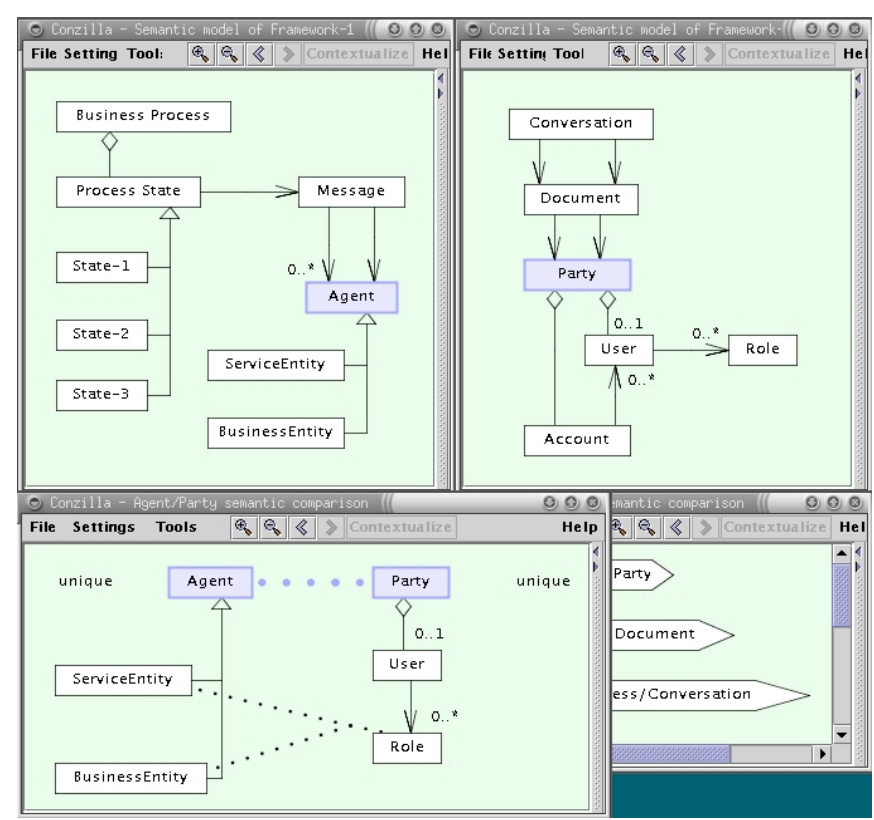

Figure 13. Double-clicking the 'Agent/Party' comparator opens the semantic comparison window (bottom left), where the similarities and the differences between the 'Agent/Party' sections of the two models are described.

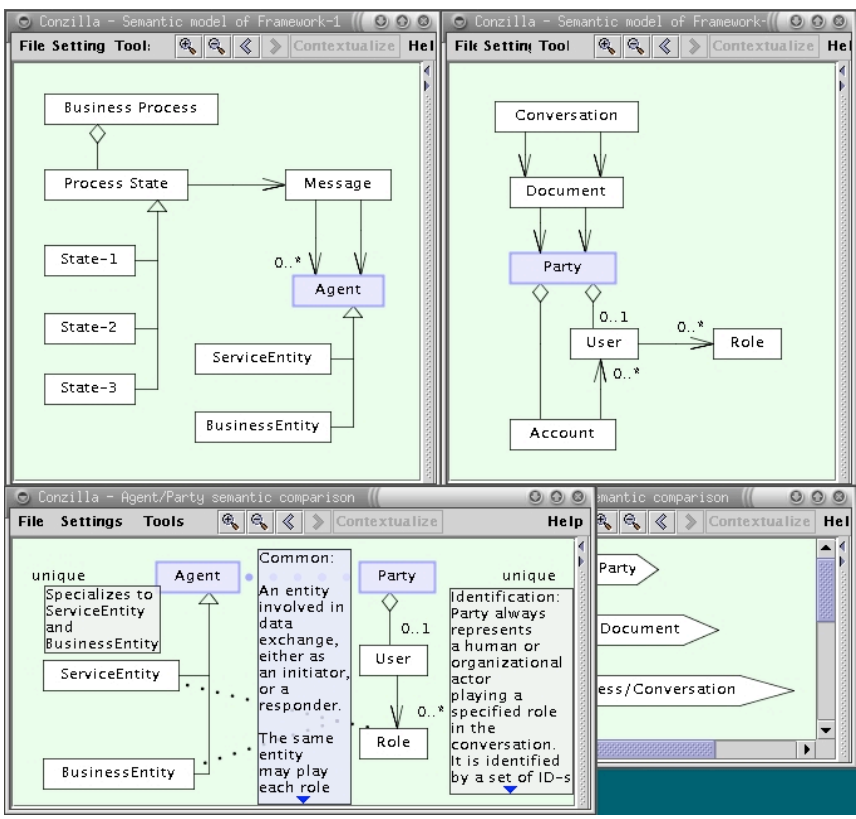

Figure 14. Similarities and differences between the concepts 'Agent' and 'Party' represented as metadata in the semantic comparison window 
As shown in Figure 14, in the semantic comparison window the similarities are represented as metadata on the dotted line between the corresponding concepts, while the differences are represented as metadata on the "unique" labels.

\section{KNOWLEDGE CREATION ON THE HUMAN SEMANTIC WEB}

\subsection{The SECI spiral of knowledge creation}

In their award-winning book from 1995 The Knowledge Creating Company [16], Nonaka and Takeuchi introduce their theory of organizational knowledge creation. According to them, the Cartesian split between subject and object, the knower and the known, has given birth to a western view of an organization as a mechanism for information processing. While this view has proven to be effective in explaining how an organization functions, it does not really explain the concepts of innovation and knowledge creation. In the Nonaka-Takeuchi theory of knowledge creation, the cornerstone is the distinction between tacit and explicit knowledge. The dominant form of knowledge in the West is explicit knowledge, which can be easily transmitted across individuals - formally and systematically. In contrast, the Japanese view knowledge as primarily tacit - something that is not easily visible and expressible, but which is deeply rooted in an individual's actions and experiences.

According to Nonaka and Takeuchi, the key to knowledge creation lies in the following four (SECI) modes of knowledge conversion, that occur when tacit and explicit knowledge interact with each other:

- Socialization, which is the process of sharing experiences (tacit knowledge), thereby creating new tacit knowledge.

- Externalization, which is the process of articulation and conversion of tacit knowledge into explicit knowledge.

- Combination, which is the process of restructuring and aggregating explicit knowledge into new explicit knowledge.

- Internalization, which is the process of reflecting on and embodying explicit knowledge into tacit knowledge.

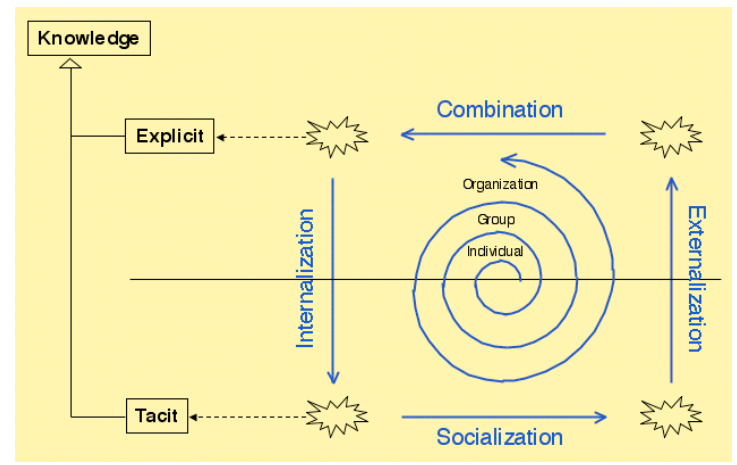

Figure 15. The SECI spiral of knowledge creation

As illustrated in Figure 15, a knowledge-creating spiral occurs when these modes of interaction between tacit and explicit knowledge are elevated from the individual, to the group and organizational levels. Organizational knowledge creation, therefore, 
should be understood as a spiraling process that organizationally amplifies the knowledge created by individuals and crystallizes it as a part of the knowledge network of the organization. This process takes place within an expanding "community of interaction" which crosses intra- and inter-organizational levels and boundaries ([28], p.51).

Nonaka and Takeuchi emphasize that, on the organizational level, the spiral of knowledge creation is driven by organizational intention, i.e. an organization's aspiration to achieve its goals. Moreover, they introduce the Japanese concept of 'ba' (which roughly means "place for interactions") as a crucial enabler for effective knowledge creation. Within an organizational context, it is the role of managers to maintain the necessary manifestations of such 'ba' in order to support the knowledge creation spiral and make it efficient for the purposes of the organization.

\subsection{Globalizing the SECI spiral}

The Human Semantic Web can be seen as a kind of 'ba' for elevating the SECI spiral of knowledge creation ${ }^{27}$ to the global level, where groups of individuals or organizations that share similar intentions can interact and create new knowledge together. Sharing experiences with others through electronically mediated "trusted interactions" can support socialization ${ }^{28}$ and generate new tacit knowledge, which can then be externalized and turned into explicit knowledge by creating contextmaps. Then, by making use of the concept-in-context methodology described in section 7.2, these context-maps can be elaborated on and extended by others, creating new explicit knowledge by combination. This explicit knowledge can in turn be reflected upon and internalized into new tacit knowledge - completing a full turn of the SECI spiral.

\subsection{Open research - a scenario from the medical domain}

The advent of informal web publishing has created unparalleled possibilities of accessing the ongoing research work of others. In conjunction with the presently exploding weblogging activities [4], this is creating the foundations for a globally annotated open research culture [61], where the value of a specific research contribution will be judged by its offspring - i.e., who will decide to reference or reuse it - and not by its offering, i.e., who will decide to publish it. The emergence of such an open research paradigm - based on what Paquet in [22] calls personal knowledge publishing - is challenging the business models of many professional publishers [27], where authors are supposed to contribute for free - only for the pleasure of being allowed to publish the results of their work under the freely supplied peer-review of their colleagues.

Here I will briefly discuss a possible open research scenario from the medical domain $^{29}$, which could bridge the present gap between medical research and practice. Figure 16 depicts the present state of "closed research" within the medical sector, as it would be described on the Human Semantic Web.

\footnotetext{
${ }^{27}$ Discussed in section 9.1.

${ }^{28}$ Of course, the critical part of this process is the "trust" part, which is far from present on the web of today. However, the SW initiative has created the prerequisites for building the necessary "web of trust", since on the SW, every resource is uniquely identifiable.

${ }^{29}$ This scenario has been worked out in collaboration with Göran Agerberg.
} 


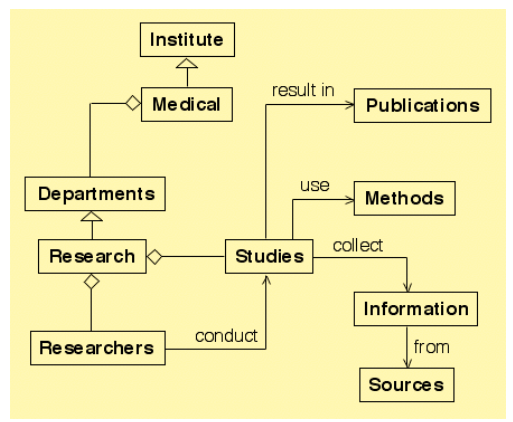

Figure 16. The present structure of closed medical research

As shown in the figure, a Medical Institute consists of Research Departments with Researchers that conduct Research Studies, which result in Publications. These Research Studies make use of Methods and collect Information that is available from different Sources.

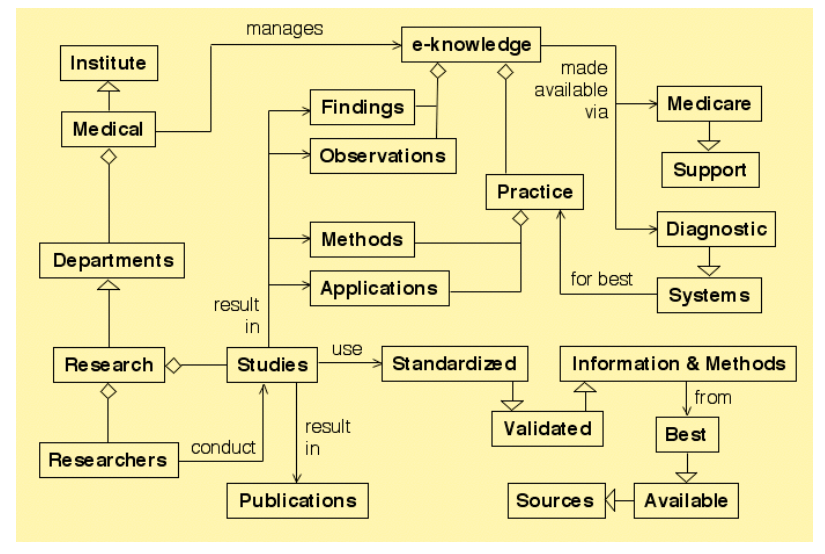

Figure 17. A possible structure for open medical research with validated feedback

A future scenario for medical research, based on a variation of the open research paradigm is described in Figure 17. Here, in addition to the descriptions of Figure 16, it is shown that Research Studies result in Findings, Observations, Methods and Applications that are part of the e-knowledge managed by the Medical Institute. This e-knowledge is in turn made available via Medical Support and Diagnostic Systems for best Practice, which enables the Research Studies to make use of Standardized Validated Information \& Methods from the Best Available Sources. Note that in this case, the concept of "open research" should be interpreted as "open research source" since it is the sources of research that are made open, while the research on this information is separated from its collection and maintenance. In this way, the Human Semantic Web could provide a basis for a fundamental restructuring of the entire health care sector, which could be turned into a transparently documented and validated process, supported by modern ICT tools, where medical practitioners would get easy access to the latest medical research findings. This is in sharp contrast to the "closed research source" situation of today, where medical research and practical health care are almost totally separated. 


\subsection{Enriching the economy by expanding the value ontology}

Figure 18 shows a Conzilla map called "Taxonomy of value types", which was created about 4 years ago in connection with a project idea called Ethical ECommerce (E2C) that we were discussing with one of our industry partners, but which, for various reasons, was not realized at the time. The aim was to make use of the Human Semantic Web as a collaborative modeling environment and try to set up a Conzilla-based 'ba' for capturing as many as possible of the different value-types that are important to some of the stakeholders in our global future - including individuals, communities and organizations on the national and international level. Then these stakeholders would create "stakeholder-specific value-profiles" for different projects - each value-profile marked ("meta-tagged") with information on the stakeholder(s) that created it. ${ }^{30}$

The E2C project could be sub-titled: Enriching the Economy by Expanding the Value Ontology - Stakeholder-Specific Value Profiling as a Mediator of Market Exchange. The specific idea was to let the operator (= market-maker) of a so-called "market hub" (= electronic market place) announce that a certain percentage (say $1 \%$ ) of the turnover of the hub would be directed to a project that the customer would be free to choose for her/himself. The system (based on Conzilla) would provide a menu of possible choices - and each project would be equipped with a set of value profiles issued by different organizations, whose relevant metadata would be available from an inspection of the value-profile itself.

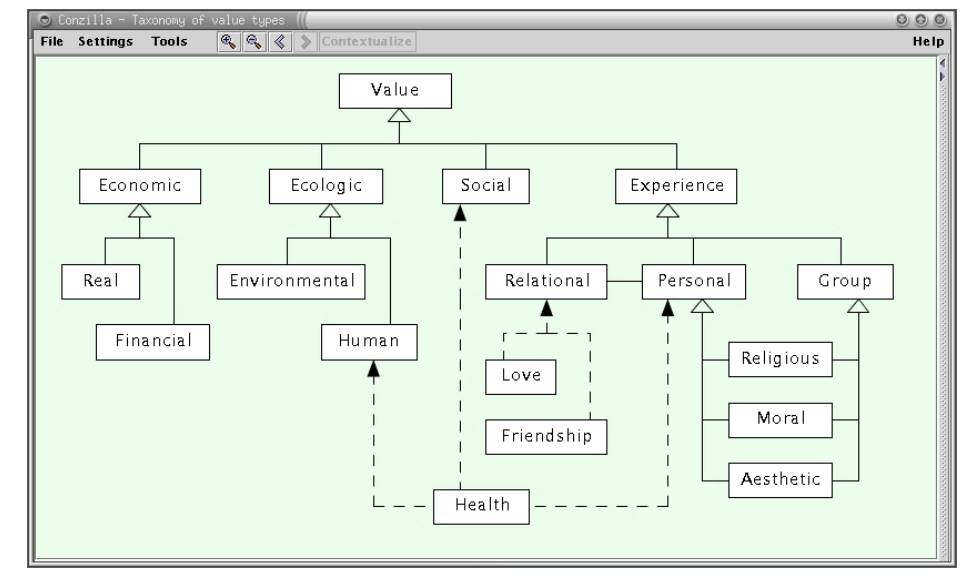

Figure 18. An embryo of an expanded value ontology

In this way, if you support e.g. Greenpeace, then you would be free to choose a project that has an attractive Greenpeace value profile, etc. The underlying idea is to supply the consumer with a whole set of group-consensus-based, stakeholderspecific value profiles that have been developed by a conceptual calibration process based on modeling of value types within the group. Such E2C-groups would of course include (but not be limited to!) various consumer groups. Then the consumer can make the choice according to the preferences (expressed in the form of a valueprofile) of the group that $\mathrm{s} /$ he places most trust in.

\footnotetext{
30 "Who" is probably the most important single piece of metadata on the web.
} 
The crucial challenge of this E2C-scheme - as briefly outlined above - is to set things up so that it will be commercially profitable to act in an ethical way. Otherwise this type of behavior will not spread among market stakeholders. Therefore all sorts of information regarding the value-profiled activities on the market-hub should be automatically fed back to the market-maker's advertising department, which can do things like displaying on their web site today's contribution by their consumers towards "making the world a better place" by supporting the following value-profiles with the following amount. In fact, I believe - as do the authors of the book Beyond Branding [3] - that it will become very profitable for a market maker to show vigorous activity in the many "non-commercial" dimensions that are reflected in the expanded value ontology. Of course, consumer-centric value modeling will require a whole chain of supervisory activities, which - if designed appropriately - will have the potential to support the democratic process as it evolves into new and unchartered electronic territory.

\subsection{Negozilla - negotiating a sustainable future for all}

The Human Semantic Web also provides the necessary 'ba' for distributed global negotiations about creating a sustainable future for all inhabitants on this planet ${ }^{31}$. In order to initiate such negotiations in a playful and creative way, we are planning to develop a Conzilla-based distributed global resource negotiation game that we call Negozilla. In order to create the necessary organizational intention for effective knowledge creation in Negozilla, each participant ${ }^{32}$ must answer 'yes' to the following two questions:

1) Do you think that there are enough resources on this planet in order for every person that inhabits it to have a decent life?

2) Are you prepared to contribute actively towards the realization of this goal?

If your answer to any one of these questions is 'no', you are not allowed to enter the game. Otherwise you are assigned your own knowledge patch (= group of layered context-maps) and invited to a global negotiation table. Since all participants have agreed that "there is enough for everybody" and "we will work towards making it happen", it follows that there is no need for all the violence-based repressive efforts that we have erected in order to protect ourselves (and our assets) from ourselves. Therefore, all the destructive "violence-supporting capital" on this planet is freed up for redistribution and can be used to support more constructive activities. This is what the online negotiations of Negozilla will be dealing with. They will take place using the methods of "concept-in-context" and "conceptual calibration" described above. The state of the negotiations and the agreed-upon actions and activities will be visualized and made available for public inspection on the web. The Negozilla negotiations will consist of several activities, including:

1) Modeling of ownership relations. "Ownership-maps" will be constructed in order to achieve a global overview of the ownership structures on this planet and highlight un-chartered areas of unknown ownership relations.

\footnotetext{
${ }^{31}$ Of course, this is closely related to the E2C project described in the last section.

${ }^{32}$ Note that 'participator' stands for both individuals and organizations. Any organization can enter the Negozilla game, provided only that its executives answer 'yes' to the two entrance questions.
} 
2) Modeling of participator contributions and needs, i.e., describing what you have to offer and what you need. This is similar to knowledge-gap based learner modeling, which is based on modeling what you know and what you would like to know, and it could be termed "earth-inhabitant modeling", "customizing your existence space" or "capturing your specs for a decent life".

3) Collaborative negotiations modeling using the conceptual calibration method outlined above. This modeling will be aimed at expanding our global value ontology ${ }^{33}$, describing our various activities with certified value-profiles, where "certified" means explicit and validated information about "who" (individual or group) that has assigned this value-profile to this activity/project, as well as when this assignment was made. Much effort will be spent on modeling and visualizing the correspondences between activities/projects, value-profiles, and certifying bodies in various ways. The overall aim here is to support the emergence of "birds-of-afeather" types of interactions between groups of individuals and organizations that have large overlaps in their respective assessments (value profiles) of a specific project. This presents a "value-pulling" way of establishing value chains that can contribute towards the overall goal of a "decent life" for all. By striving towards this goal (which of course can never be fully achieved) we contribute towards the construction of a transnational corporation that could be called "Humanity Inc." where the "Inc" stands for "Incorporated as individuals".

The most important effect of Negozilla is that even though - or in fact just because it is "just a game", it should be able to transparently provide descriptions of constructive scenarios for the future of all inhabitants on this planet in a way that is accessible for a substantial (and rapidly increasing) part of these inhabitants. In this way, Negozilla can be expected to externalize and make available some of the utopian visions of the future that are dangerously lacking in real politics, and from which we can internalize and socialize the inspiring and innovative ideas that are so desperately needed in order to create a constructive and sustainable future for us all.

\section{SUMMARY AND CONCLUSIONS}

In this paper I have argued that with the advance of new technologies like the semantic web, it becomes a necessity to change the knowledge and learning management paradigm from the current "push approach" to an individualized "pull approach" - focusing on the user rather than on the non-flexible standardized approaches of today. I have introduced the Human Semantic Web - structured in the form of a knowledge manifold and conceptually described in terms of Unified Language Modeling - and I have argued that it has the representational and presentational power to effectively support the knowledge-pulling paradigm.

Moreover, I have introduced semantic isolation, coexistence and collaboration as three distinctive levels of semantic interoperability, and explained how our conceptual web browser Conzilla can help to achieve semantic collaboration in a bottom-up way by building "ontological bridges" between different conceptual models, using the conceptual calibration technique. Finally, I have introduced the Nonaka-Takeuchi theory of knowledge creation and shown how the Human

\footnotetext{
${ }^{33}$ as described in section 9.4 .
} 
Semantic Web could provide an interaction space for elevating their SECI spiral of knowledge creation to the global level. In three different futuristic scenarios I have tried to outline what kind of impact it could have if knowledge would be collaboratively created and shared on the global level, instead of being kept secret for various reasons.

Two thousand five hundred years ago, Pythagoras taught us that unselfish knowledge is the best way to purify our souls. Today economists and politicians tell us that selfish knowledge is the best way to fill our wallets. Hence, the catharsis-oriented knowledge philosophy of the Pythagoreans has been complemented with the utilityoriented knowledge economy of the modern information society. The vision of this emerging knowledge economy has been convincingly formulated in the book "Transforming e-Knowledge" [17], where it is stated that:

In the Knowledge Economy, those individuals and enterprises that share and process their knowledge effectively have a great advantage. To keep up, most of us will need a quantum leap in our ability to manage knowledge. This won't happen without a genuine transformation in the ways in which we appraise what we know, what we can do with it, and what we need to know. [...] Through this transformation, learning and knowledge management will be fused in both theory and practice. This synthesis will form the core of a new social and economic system based on knowledge sharing. This transformation is underway. Participation in shaping the transformation is mandatory for all hoping to achieve success in the Knowledge Economy.

Although the utility-oriented knowledge economy is strategically important for our future, we cannot afford to neglect the catharsis-oriented knowledge philosophy if the quality of the learning process is to be maintained ${ }^{34}$. The great strategic challenge, upon which our future on this planet hinges, is to transcend these opposing knowledge perspectives and achieve a dialectical synthesis of the selfish and unselfish views of knowledge. In this article, I have tried to indicate how the Human Semantic Web could contribute to this synthesis - an aspiration that inspires the work of my entire research group.

\section{ACKNOWLEDGEMENTS}

I acknowledge my gratitude to the members of the KMR group and especially to Mikael Nilsson and Matthias Palmér for their contributions to many of the subjects that have been discussed in this article. I am also grateful to Miltiadis Lytras, without whose persuasive powers this article would not have been written. Finally, I acknowledge the contributions of several members of our international networks, notably WGLN [42], Prolearn [38], SIGSEMIS [44] and Sakai [49].

\footnotetext{
${ }^{34}$ This is known by everyone that is deeply involved in education.
} 


\section{REFERENCES}

\section{Papers and books}

[1] Blomqvist, U. \& Handberg, L. \& Naeve, A., New Methods for focusing on Students' Learning Process and Reflection in Higher Education. Proc. of the $28^{\text {th }}$ IUT (Improving University Teaching) Conference, Växjö: May 2003.

[2] Gruber, T. (2004) Every ontology is a treaty - a social agreement - among people with some common motive in sharing, Interviewed by Miltiadis Lytras in AIS SIGSEMIS Bulletin 1(3), October 2004.

[3] Ind, N. (2003) (ed.), Beyond Branding - how the new values of transparency and integrity are changing the world of brands, Kogan Page Limited, ISBN 07494-4115-1.

[4] Mortensen, T., Walker, J. (2002) Blogging thoughts: personal publication as a research tool, http://www.intermedia.uio.no/konferanser/skikt02/docs/Researching ICTs in context-Ch11-Mortensen-Walker.pdf

[5] Naeve, A. (1997) The Garden of Knowledge as a Knowledge Manifold - A Conceptual Framework for Computer Supported Subjective Education, CID-17, TRITA-NA-D9708, Department of Numerical Analysis and Computing Science, KTH, Stockholm, 1997, http://cid.nada.kth.se/sv/pdf/cid_17.pdf.

[6] Naeve, A. (1999) Conceptual Navigation and Multiple Scale Narration in a Knowledge Manifold, CID-52, TRITA-NA-D9910, Department of Numerical Analysis and Computing Science, KTH, 1999. http://cid.nada.kth.se/sv/pdf/cid 52.pdf.

[7] Naeve, A.. (2001a) The Concept Browser - a New Form of Knowledge Management Tool, Proceedings of the $2^{\text {nd }}$ European Web-Based Learning Environment Conference (WBLE 2001), Lund, Sweden, Oct. 24-26, 2001, http://kmr.nada.kth.se/papers/ConceptualBrowsing/ConceptBrowser.pdf

[8] Naeve, A. (2001b) The Knowledge Manifold - an Educational Architecture that supports Inquiry-Based Customizable Forms of E-Learning, Proc. of the $2^{\text {nd }}$ European Web-Based Learning Environment Conference, Lund, Sweden, Oct.24-26, 2001.

[9] Naeve, A., Nilsson, M., Palmér, M. (2001) The Conceptual Web-our research vision, Proceedings of the first Semantic Web Working Symposium, Stanford, July 2001, www.semanticweb.org/SWWS/program/position/soi-nilsson.pdf.

[10] Naeve, A., Knudsen, C., Nilsson, M., Palmér, M., Paulsson, F., Petersson, A., Müller, E., Pargman, D., Blomqvist, U. (2002) En publik e-lärandeplattform byggd på kunskapsmångfalder, öppen källkod och öppna IT-standarder, (A public e-learning platform based on knowledge manifolds, open source and open, international ICT standards. Report to the Swedish Netuniversity. Nov. 2002, http://kmr.nada.kth.se/papers/SemanticWeb/Natuniv-KMR.pdf.

[11] Naeve, A., Nilsson, M., Palmér, M., Paulsson, F. (2005) Contributions to a Public e-Learning Platform - Infrastructure, Architecture, Frameworks and Tools, International Journal of Learning Technology (IJLT), Vol 1, No. 3, pp. 352-381, 2005, http://kmr.nada.kth.se/papers/SemanticWeb/Contrib-to-PeLP.pdf

[12] Nejdl. W., Wolf, B., Qu, C., Decker, S., Sintek, M., Naeve, A., Nilsson, M., Palmér, M., Risch, T. (2002) Edutella: A P2P Networking Infrastructure Based on $R D F$, Proc. of the 11th World Wide Web Conference (WWW2002), Hawaii, May 7-11, 2002. http://kmr.nada.kth.se/papers/SemanticWeb/p597-nejdl.pdf 
[13] Nejdl, W., et al. (2001) PADLR (Personalized Access to Distributed Learning Repositories) proposal to WGLN, granted in March 2001, www.learninglab.de/pdf/L3S_padlr_17.pdf

[14] Nilsson, M., Palmér, M., Naeve, A. (2002) Semantic Web Metadata for eLearning - Some Architectural Guidelines, Proceedings of the 11th World Wide Web Conference, Hawaii, May 7-11, 2002. http://kmr.nada.kth.se/papers/SemanticWeb/p744-nilsson.pdf

[15] Nilsson, M., Naeve, A., Palmér, M. (2004) The Edutella P2P NetworkSupporting Democratic E-Learning and Communities of Practice, in McGreal, R. (ed.), Online Education Using Learning Objects, Routledge-Falmer, New York, 2004, ISBN 0-415-33512-4, http://kmr.nada.kth.se/papers/SemanticWeb/Edutella-chapter.pdf

[16] Nonaka, I., Takeuchi, H. (1995) The Knowledge-Creating Company: How Japanese companies Create the Dynamics of Innovation, New York: Oxford Univ. Press.

[17] Norris, D., Mason, J., Lefrere, P. (2003) Transforming e-Knowledge, Society for College and University Planning, Ann Arbor, Michigan, ISBN 0-9700413-2-2.

[18] Novak, J. D., The Theory Underlying Concept Maps and How to Construct Them, http://cmap.coginst.uwf.edu/info/.

[19] Odell \& Martin (1998) Object-Oriented Methods - a Foundation, Prentice Hall.

[20] Palmér, M., Naeve, A. (2005) Conzilla - a Conceptual Interface to the Semantic $W e b$, Invited paper at the 13:th International Conference on Conceptual Structures (ICCS 2005), Kassel, July 18-22, 2005.

[21] Palmér, M. \& Naeve, A. \& Paulsson, F., The SCAM-framework-helping applications to store and access metadata on the semantic web, Proceedings of the First European Semantic Web Symposium (ESWC 2004), Heraklion, Greece, May, 2004, Springer, ISBN 3-540-21999-4, http://kmr.nada.kth.se/papers/SemanticWeb/SCAM-ESWS.pdf.

[22] Paquet, S., Personal knowledge publishing and its uses in research, http://radio.weblogs.com/0110772/stories/2002/10/03/personalKnowledgePublis hingAndItsUsesInResearch.html

[23] Pettersson, D. (2000) Aspect Filtering as a Tool to Support Conceptual Exploration and Presentation, TRITA-NA-E0079, CID/NADA/KTH, http://kmr.nada.kth.se/papers/ConceptualBrowsing/AspectFiltering-exjobb.pdf

[24] Powell, A., Nilsson, M., Naeve, A., Johnston, P. (2004) DCMI - Abstract Model, DCMI working draft, http://dublincore.org/documents/abstract-model

[25] Poincaré, H., Science and Hypothesis, Dover Publ. Inc., New York 1952 (1905).

[26] Rumbaugh, J., Jacobsson, I., Booch, G. (1999) The Unified Modeling Language Reference Manual, Addison Wesley Longman Inc., 1999.

[27] Smith, J. W. T., The Deconstructed Journal - A New Model for Academic Publishing, Learned Publishing, Vol. 12, No. 2, April 1999, ISSN 0953-1513, http://library.kent.ac.uk/library/papers/jwts/d-journal.htm

[28] Takeuchi, H., Nonaka, I. (2004) Hitotsubashi on Knowledge Management, Wiley \& Sons, ISBN 0-470-82074-8.

[29] Wilson, S. (2001) The Next Wave: CETIS interviews Mikael Nilsson about the Edutella project, Feature article, Centre for Educational Technology Interoperability Standards (CETIS), September 2001, http://kmr.nada.kth.se/papers/SemanticWeb/TheNextWave.pdf

[30] Wittgenstein, L. (1953) Philosophical investigations, Basil Blackwell, Oxford. 
Web sites

[31] KMR (Knowledge Management Research) group: http://kmr.nada.kth.se

[32] ULL (Uppsala Learning Lab): www.ull.uu.se

[33] Confolio: www.confolio.org

[34] Conzilla: www.conzilla.org

[35] SCAM: http://scam.sourceforge.net

[36] SHAME: http://kmr.nada.kth.se/shame

Demo-editor: http://knowgate.nada.kth.se:8180/SHAME/DemoEditor.jsp

[37] VWE (Virtual Workspace Environment): www.vwe.nu

[38] Prolearn: http://www.prolearn-project.org

[39] JXTA: http://www.jxta.org

[40] Edutella: http://edutella.jxta.org

[41] UDBL (Uppsala Data Base Laboratory): www.dis.uu.se/ udbl.

[42] WGLN (Wallenberg Global Learning Network): www.wgln.org.

[43] Prolearn: www.prolearn-project.org

[44] SIGSEMIS: www.sigsemis.org

[45] RDF (Resource Description Framework): www.w3.org/RDF.

[46] RDFS (RDF-Schema): www.w3.org/TR/rdf-schema

[47] OWL (Web Ontology Language): www.w3.org/TR/owl-features

[48] Semantic Web initiative: www.SemanticWeb.org.

[49] Sakai: www.sakaiproject.org

[50] e-Europe: http://europa.eu.int/information society/eeurope/index en.htm.

[51] ECIMF (Electronic Commerce Integration Meta-Framework): www.ecimf.org.

[52] ebXML: www.ebxml.org.

[53] UN/CEFACT www.unece.org/cefact.

[54] RosettaNet: www.rosettanet.org.

[55] BizTalk: www.microsoft.com/biztalk/techinfo/BizTalkFramework20.doc.

[56] Dublin Core Metadata Initiative: http://dublincore.org

[57] LOM-RDF-binding: http://kmr.nada.kth.se/el/ims/metadata.html

[58] UML (Unified Modeling Language): http://www.uml.org

[59] Concept maps: http://www.graphic.org/concept.html

[60] Topicmaps: www.topicmaps.net, www.topicmaps.org.

[61] Seb's Open research: http://radio.weblogs.com/0110772

\section{ABOUT THE AUTHOR}

Ambjörn Naeve (www.nada.kth.se/ amb) has a background in mathematics and computer science and earned his PhD in computer science from KTH in 1993. He is presently the coordinator of research on interactive learning environments and the Semantic Web at the School of Computer Science and Communication (Nada) at the Royal Institute of Technology $(\mathrm{KTH})$ in Stockholm, where he heads the Knowledge Management Research group (KMR: http://kmr.nada.kth.se). He has been involved with research and development of interactive learning environments since he initiated the Garden of Knowledge project at Nada in 1996. He has also taught mathematics at KTH since 1967 and in the last two decades he has headed the development of several tools for ICT-enhanced mathematics education (http://kmr.nada.kth.se/math). Ambjörn Naeve is also a well-known industry consultant with extensive experience in various forms of modeling for software engineering and business applications. He has invented the concept browser Conzilla (www.conzilla.org) and has developed a modeling technique 
called Unified Language Modeling (http://kmr.nada.kth.se/cm), based on UML, which has been designed to "draw how we talk about things," (i.e., to depict conceptual relationships in a linguistically coherent way).

Over the last decade the KMR group has developed an information architecture (the Knowledge Manifold), an infrastructure (Edutella), two frameworks (SCAM and $S H A M E$ ) and number of tools (Formulator, Meditor, VWE, Confolio and Conzilla). These items should be considered as contributions towards a publicly accessible Knowledge and Learning Management Environment, based on open source and open international ICT standards as well as on Semantic Web technology. The KMR group is active within several international networks for technologyenhanced learning and Semantic Web, notably WGLN, Prolearn, SIGSEMIS, and Sakai. 